\title{
Landsat Ecosystem Disturbance Adaptive Processing System (LEDAPS) Algorithm Description
}

Open-File Report 2013-1057 



\section{Landsat Ecosystem Disturbance Adaptive Processing System (LEDAPS) Algorithm Description}

By Gail Schmidt, Calli Jenkerson, Jeffrey Masek, Eric Vermote, and Feng Gao

Open-File Report 2013-1057 


\section{U.S. Department of the Interior \\ KEN SALAZAR, Secretary}

\section{U.S. Geological Survey \\ Suzette M. Kimball, Acting Director}

U.S. Geological Survey, Reston, Virginia: 2013

For more information on the USGS - the Federal source for science about the Earth, its natural and living resources, natural hazards, and the environment, visit http://www.usgs.gov or call 1-888-ASK-USGS.

For an overview of USGS information products, including maps, imagery, and publications, visit http://www.usgs.gov/pubprod

To order this and other USGS information products, visit http://store.usgs.gov

Any use of trade, firm, or product names is for descriptive purposes only and does not imply endorsement by the U.S. Government.

Although this information product, for the most part, is in the public domain, it also may contain copyrighted materials as noted in the text. Permission to reproduce copyrighted items must be secured from the copyright owner.

Suggested citation:

Schmidt, G.L., Jenkerson, C.B., Masek, J., Vermote, E., and Gao, F., 2013, Landsat ecosystem disturbance adaptive processing system (LEDAPS) algorithm description: U.S. Geological Survey Open-File Report 2013-1057, 17 p. 


\section{Contents}

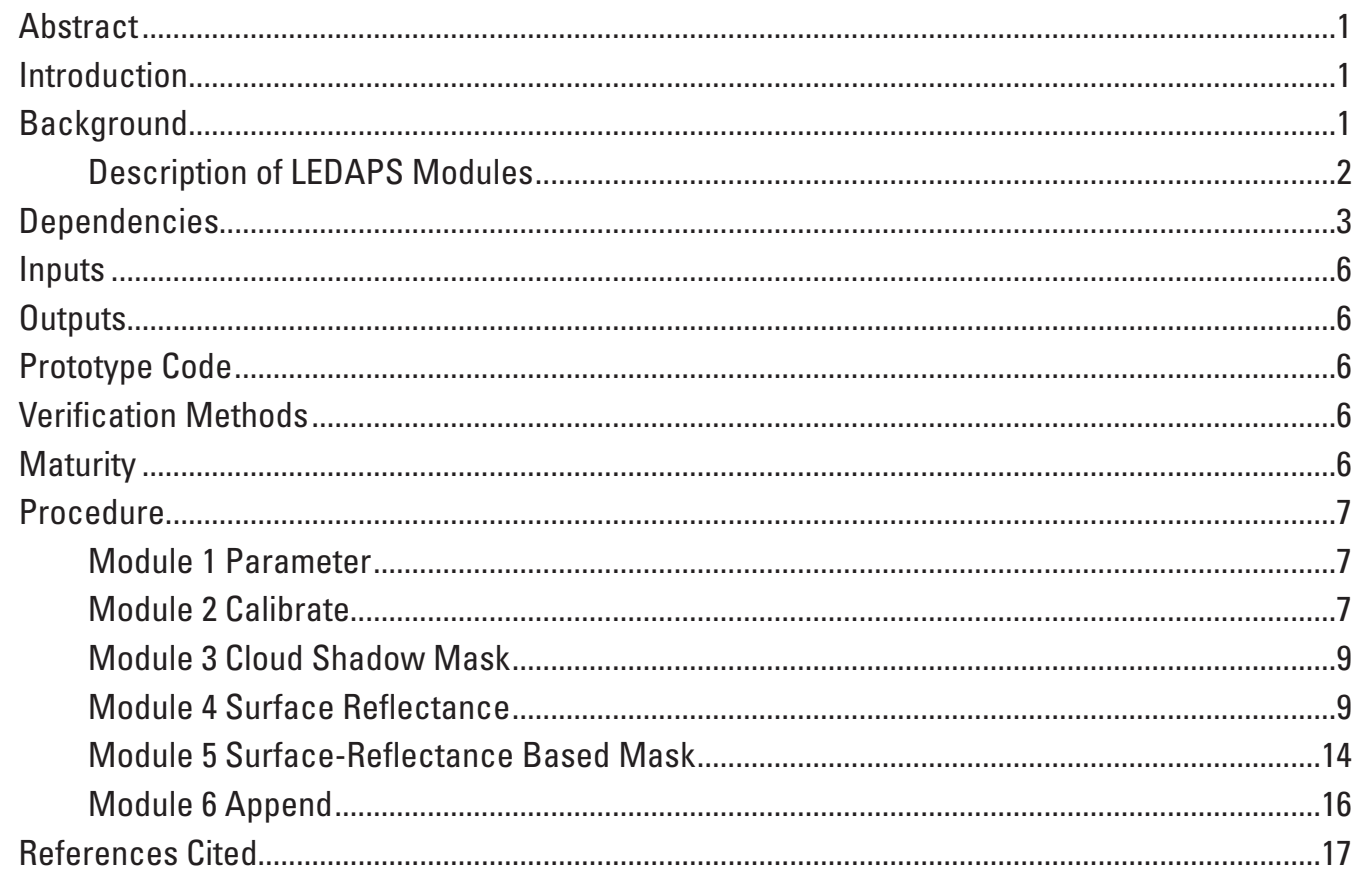

\section{Figures}

1. Images showing examples of atmospheric correction results.........................................2

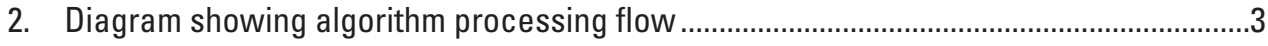

3. Diagram showing atmospheric correction flow ...............................................................10

\section{Tables}

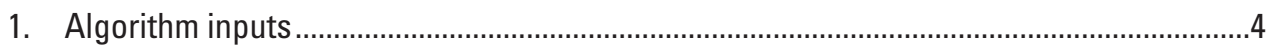

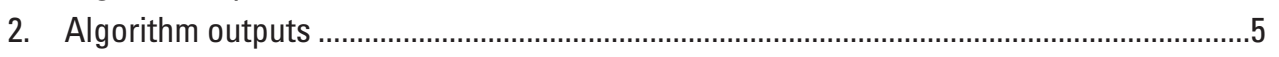


Conversion Factors

SI to Inch/Pound

\begin{tabular}{lcl}
\hline \multicolumn{1}{c}{ Multiply } & By & \multicolumn{1}{c}{ To obtain } \\
\hline centimeter $(\mathrm{cm})$ & Length & inch \\
meter $(\mathrm{m})$ & 0.3937 & foot $(\mathrm{ft})$ \\
kilometer $(\mathrm{km})$ & 3.281 & mile $(\mathrm{mi})$ \\
kilometer $(\mathrm{km})$ & 0.6214 & mile, nautical $(\mathrm{nmi})$ \\
meter $(\mathrm{m})$ & 0.5400 & yard $(\mathrm{yd})$ \\
\hline & 1.094 & \\
\hline square meter $\left(\mathrm{m}^{2}\right)$ & Area & acre \\
square meter $\left(\mathrm{m}^{2}\right)$ & 0.0002471 & square foot $\left(\mathrm{ft}^{2}\right)$ \\
kilogram per square meter $\left(\mathrm{kg} / \mathrm{m}^{2}\right)$ & 10.76 & pound per square foot $\left(\mathrm{lb} / \mathrm{ft}^{2}\right)$ \\
gram per square centimeter $\left(\mathrm{g} / \mathrm{cm}^{2}\right)$ & 0.2048 & xxx \\
\hline
\end{tabular}

Temperature in degrees Celsius $\left({ }^{\circ} \mathrm{C}\right)$ may be converted to degrees Fahrenheit $\left({ }^{\circ} \mathrm{F}\right)$ as follows:

${ }^{\circ} \mathrm{F}=\left(1.8 x^{\circ} \mathrm{C}\right)+32$

Vertical coordinate information is referenced to the World Geodetic System 1984 (WGS 84).

Horizontal coordinate information is referenced to the World Geodetic System 1984 (WGS 84).

\section{Abbreviations and Acronyms}

6S

ACCA

ACCESS

AOT

CDR

DDV

DEM

DN

ECV

ENVI

EROS

ETM+

GCM

GeoTIFF

GMT

GNEW

GOLD

GSFC

HDF

IDL

lat/long

LEDAPS

LMAX

LMIN
Second Simulation of a Satellite Signal in the Solar Spectrum

Automated Cloud Cover Assessment

Advancing Collaborative Connections for Earth System Science

aerosol optical thicknesses

Climate Data Record

dense dark vegetation

digital elevation model

digital number

Essential Climate Variable

Exelis Visualization Solutions

Earth Resources Observation and Science

Enhanced Thematic Mapper Plus

Global Climate Model

Georeferenced Tagged Image File Format

Greenwich Mean Time

Gain variable for Landsat 5 TM - new

Gain variable for Landsat 5 TM - old

Goddard Space Flight Center

Hierarchical Data Format

Interactive Data Language

latitude/longitude

Landsat Ecosystem Disturbance Adaptive Processing System

Spectral radiance scaled to maximum QCAL

Spectral radiance scaled to minimum OCAL 


$\begin{array}{ll}\text { LPGS } & \text { Level } 1 \text { Product Generation System } \\ \text { LUT } & \text { look up table } \\ \text { MODIS } & \text { Moderate Resolution Imaging Spectroradiometer } \\ \text { NASA } & \text { National Aeronautics and Space Administration } \\ \text { NCEP } & \text { National Centers for Environmental Prediction } \\ \text { NDSI } & \text { normalized difference snow index } \\ \text { NLAPS } & \text { National Landsat Archive Production System } \\ \text { NOAA } & \text { National Oceanic and Atmospheric Administration } \\ \text { OMI } & \text { Ozone Monitoring Instrument } \\ \text { OA } & \text { quality assurance } \\ \text { OCAL } & \text { Quantized calibrated pixel value in DN } \\ \text { SWIR } & \text { shortwave infrared } \\ \text { TIROS } & \text { Television and Infrared Observation Satellite } \\ \text { TM } & \text { Thematic Mapper } \\ \text { TOA } & \text { top of atmosphere } \\ \text { TOMS } & \text { Total Ozone Mapping Spectrometer } \\ \text { TOVS } & \text { TIROS Operational Vertical Sounder } \\ \text { UL } & \text { upper left } \\ \text { UMD } & \text { University of Maryland } \\ \text { USGS } & \text { U.S. Geological Survey } \\ \text { WO } & \text { work order }\end{array}$




\section{Acknowledgments}

The authors acknowledge Eric Vermote, Nazmi Saleous, Jonathan Kutler, and Robert Wolfe of the National Aeronautics and Space Administration (NASA) Goddard Space Flight Center (GSFC), with support from Jeff Masek of the NASA Terrestrial Ecology Program, who developed the original Landsat Ecosystem Disturbance Adaptive Processing System (LEDAPS) software. The authors also acknowledge Feng Gao of the Goddard Space Flight Center/Earth Resources Technology (ERT), with support from the NASA Advancing Collaborative Connections for Earth System Science (ACCESS) Program and the U.S. Geological Survey (USGS) Landsat Program, for the original code, which was adapted to build the baseline version of LEDAPS: 1.0.0. Lastly, the authors acknowledge David Hill and Jason Werpy of Information Dynamics, Adam Dosch of ERT, and Tom Maiersperger of Stinger Ghaffarian Technologies, Inc., with support from the USGS Landsat Data Continuity Mission (LDCM), for implementing LEDAPS 1.0.0 at the USGS Earth Resources Observation and Science (EROS) Center as an on-demand processing system, which was performed under contract G10PC00044.

The authors would also like to acknowledge John Dwyer of the USGS for his support of the ondemand processing and Landsat CDRs and ECVs, including the surface reflectance CDR.4. 


\title{
Landsat Ecosystem Disturbance Adaptive Processing System (LEDAPS) Algorithm Description
}

\author{
By Gail Schmidt', Calli Jenkerson², Jeffrey Masek ${ }^{3}$, Eric Vermote ${ }^{4}$, Feng Gao ${ }^{5}$
}

\begin{abstract}
The Landsat Ecosystem Disturbance Adaptive Processing System (LEDAPS) software was originally developed by the National Aeronautics and Space Administration-Goddard Space Flight Center and the University of Maryland to produce topof-atmosphere reflectance from Landsat Thematic Mapper and Enhanced Thematic Mapper Plus Level 1 digital numbers and to apply atmospheric corrections to generate a surface-reflectance product. The U.S. Geological Survey (USGS) has adopted the LEDAPS algorithm for producing the Landsat Surface Reflectance Climate Data Record. This report discusses the LEDAPS algorithm, which was implemented by the USGS.
\end{abstract}

\section{Introduction}

The U.S. Geological Survey (USGS) is developing science-quality, applications-ready, key terrestrial variables and will produce them on an operational basis using historical, current, and future Landsat observations. The terrestrial variables will follow the guidelines established through the Global Climate Observing System and include Climate Data Records (CDRs), which represent geophysical transformations of Landsat data, and Essential Climate Variables (ECVs), which represent specific geophysical and biophysical land properties. CDRs and ECVs offer a framework for producing long-term Landsat datasets suited for monitoring, characterizing, and understanding land-surface change over time.

This document provides a description of the Landsat Ecosystem Disturbance Adaptive Processing System (LEDAPS; Wolfe and others, 2004; Vermote and Saleous, 2007; National Aeronautics and Space Administration, 2007) algorithm, which was implemented by the USGS to produce a Landsat Surface Reflectance CDR.

\section{Background}

The LEDAPS software was originally developed in 2006 at National Aeronautics and Space Administration (NASA) Goddard Space Flight Center (GSFC) and the University of Maryland with funding from the NASA Terrestrial Ecosystems and Applied Sciences Programs. A February 2011 version was released through the NASA Advancing Collaborative Connections for Earth System Science (ACCESS) Program (Masek and others, 2006), with a contribution from the USGS Landsat Program. The USGS Earth Resources Observation and Science (EROS) Center used that version to create a baseline version of LEDAPS: 1.0.0.

${ }^{1}$ Stinger Ghaffarian Technologies (SGT), contractor to the U.S. Geological Survey (USGS) Earth Resources Observation and Science (EROS) Center, Sioux Falls, SD, work performed under contract G10PC00044.

${ }^{2}$ ERT, contractor to USGS EROS Center, Sioux Falls, SD, work performed under contract G10PC00044.

${ }^{3}$ National Aeronautics and Space Administration, Earth Observing System, Code 618, Goddard Space Flight Center, Greenbelt, MD.

${ }^{4}$ Department of Geographical Sciences, University of Maryland, College Park, MD.

${ }^{5}$ U.S. Department of Agriculture, Agricultural Research Service, Hydrology and Remote Sensing Laboratory, 10300 Baltimore Avenue, Beltsville, MD. 
LEDAPS 1.0.0 produces top-of-atmosphere (TOA) reflectance from Landsat Thematic Mapper (TM) and Enhanced Thematic Mapper Plus (ETM+) Level 1 digital numbers (DN) and applies atmospheric corrections to generate a surface-reflectance product. The corrections are based on the Second Simulation of a Satellite Signal in the Solar Spectrum (6S; Kotchenova and others, 2006; Vermote and others, 1997) radiative-transfer model used by the Moderate Resolution Imaging Spectroradiometer (MODIS) Land Science Team. Examples of the results, compared to TOA reflectance, are displayed in figure 1.
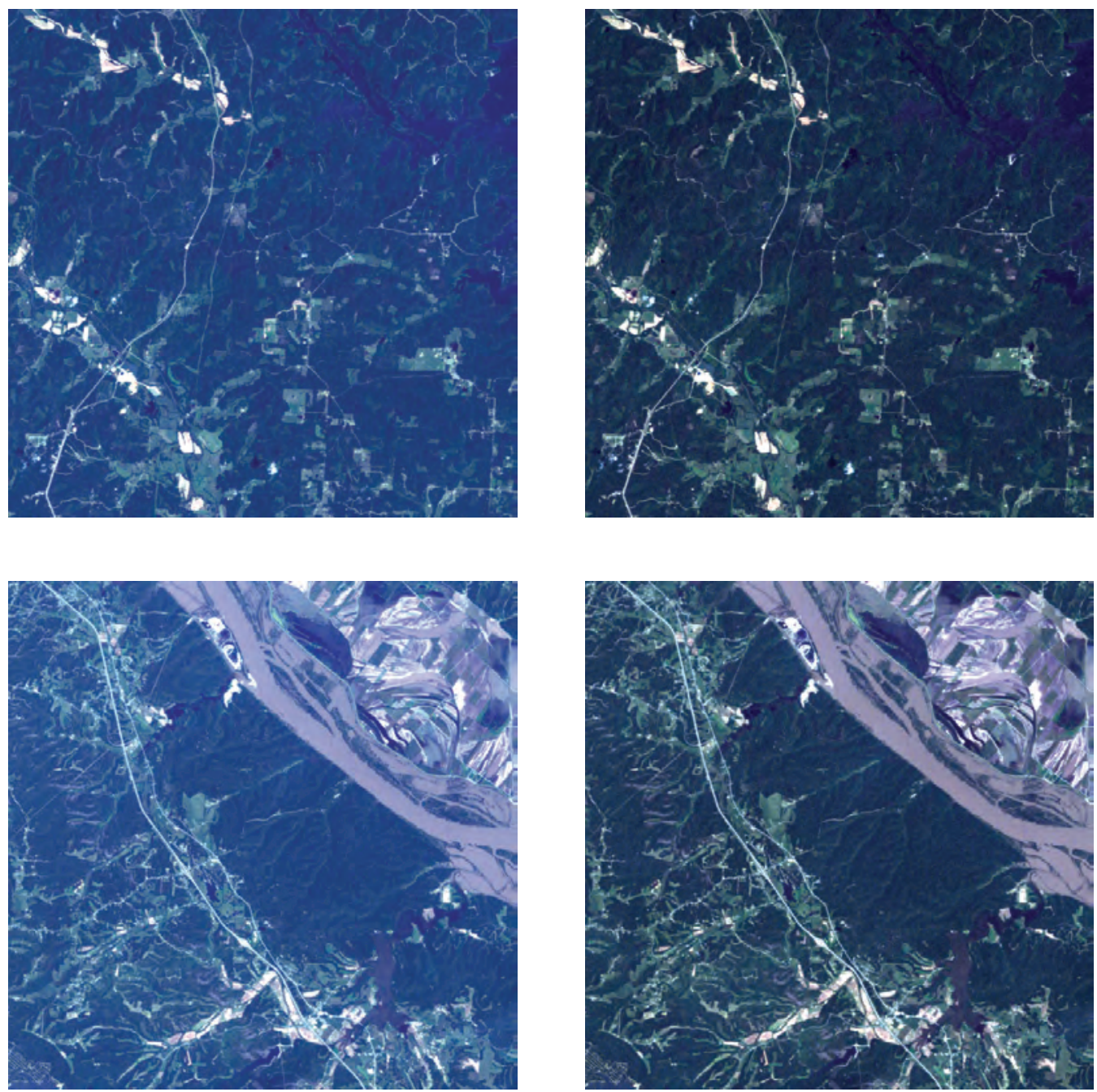

Figure 1. Examples of atmospheric correction results. All images are Landsat 5 Thematic Mapper acquired May 30, 1995 in Path 23, Row 34 spanning the Mississippi River in Missouri. The images in the right column are surface reflectance data derived from the atmospheric correction of the top of atmosphere reflectance shown in the left column.

\section{Description of LEDAPS Modules}

LEDAPS is written in six modules to execute the following three key steps:

1. Convert DN to TOA reflectance

2. Detect cloud pixels based on the TOA reflectance

3. Correct to surface-reflectance from TOA reflectance and auxiliary datasets

The modules provided in the LEDAPS software are described below, and the overall processing flow is depicted in figure 2.

Module 1 Parameter.- "Indpm" parses the Landsat metadata file and creates the necessary input files for each of the downstream LEDAPS modules.

Module 2 Calibration.- "Indcal" calibrates Landsat data from DN to TOA reflectance (and brightness temperature for the thermal band). 


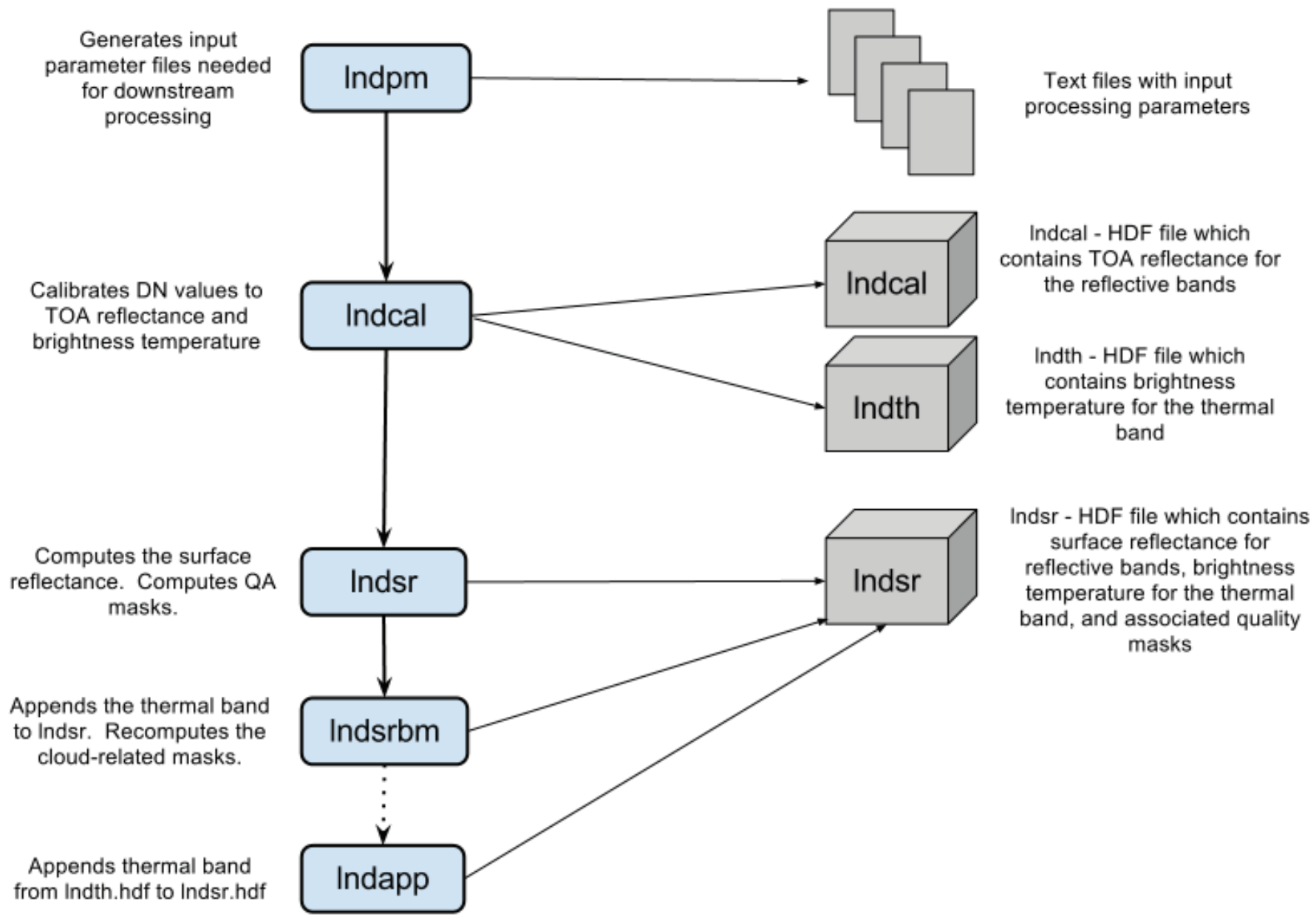

Figure 2. Algorithm processing flow.

Module 3 Cloud Shadow Mask. - "Indcsm” produces a cloud mask based on a pre-2004 C translation of an Interactive Data Language (IDL) Automated Cloud Cover Assessment (ACCA) algorithm. Note that this is an outdated and inaccurate ACCA algorithm intended for use as a preliminary cloud filter and the USGS implementation of LEDAPS 1.0.0 excludes this module.

Module 4 Surface Reflectance.- "Indsr" computes the surface-reflectance for the TM and ETM+ reflectance bands and produces a quality mask for fill, dark dense vegetation (DDV), snow, and land/water data. It includes a derivation of select internal cloud mask values used in production, but these are reset in the "Indsrbm" module.

Module 5 Surface Reflectance Based Mask._- "Indsrbm” detects and creates masks for cloud, cloud shadow, and adjacent clouds using a surface-reflectance based algorithm.

Module 6 Append.- "Indapp" appends the thermal brightness temperature band to the surface-reflectance output product.

\section{Dependencies}

The LEDAPS modules are designed to work with formatting specific to Landsat TM and ETM+ scenes and the auxiliary datasets needed to perform atmospheric corrections. Processing is dependent upon

- $\quad$ Properly formatted Landsat TM or ETM+ metadata files,

- Georeferenced Tagged Image File Format (GeoTIFF) band data, and

- Air pressure, water vapor, air temperature, ozone, and digital elevation model (DEM) data. 
Table 1. Algorithm inputs.

\begin{tabular}{|c|c|c|c|c|}
\hline Module & Description & Units & Source & Type \\
\hline \multirow[t]{2}{*}{ Indpm } & Landsat metadata file & & $\begin{array}{l}\text { LPGS, NLAPS, } \\
\text { NLAPS WO, } \\
\text { UMD (TM or } \\
\text { ETM }+ \text { ) }\end{array}$ & Text file. \\
\hline & $\begin{array}{l}\text { Path to the auxiliary files: GCMDEM, OMI/ } \\
\text { TOMS, NCEP REANALYSIS data, and } \\
\text { GOLD/GNEW calibration files for TM }\end{array}$ & & ANC_PATH & $\begin{array}{l}\text { Environment } \\
\text { variable. }\end{array}$ \\
\hline \multirow[t]{3}{*}{ Indcal } & Calibration input parameter file (lndcal.txt) & & lndpm & Text file. \\
\hline & Input metadata file (metadata.txt) & & lndpm & Text file. \\
\hline & $\begin{array}{l}\text { GOLD, GNEW, GOLD_2003 (if processing } \\
\text { TM data) }\end{array}$ & Gains per band, $\mathrm{W} /(\mathrm{m} 2$ sr micron $)$ & Landsat cal/val team & Text file. \\
\hline \multirow[t]{3}{*}{ lndcsm } & Cloud mask input parameter file (lndesm.txt) & & lndpm & Text file. \\
\hline & $\begin{array}{l}\text { Landsat calibrated TOA reflectance (bands } \\
\text { 1-7) }\end{array}$ & Reflectance & lndcal & HDF4 file. \\
\hline & Landsat thermal band brightness temperature & ${ }^{\circ}$ Celsius & lndcal & HDF4 file. \\
\hline \multirow[t]{4}{*}{ Indsr } & $\begin{array}{l}\text { TOA reflectance for all reflective bands (lnd- } \\
\text { cal.hdf) }\end{array}$ & $\begin{array}{l}\text { Reflectance, signed 16-bit integer, scale } \\
\text { factor } 0.0001\end{array}$ & lndcal & HDF4 file. \\
\hline & $\begin{array}{l}\text { QA bits to indicate band saturation (lndcal. } \\
\text { hdf) }\end{array}$ & Flag, unsigned byte & lndcal & HDF4 file. \\
\hline & $\begin{array}{l}\text { NCEP REANALYSIS data (pressure, water } \\
\text { vapor, air temperature) }\end{array}$ & $\begin{array}{l}\text { Signed } 16 \text {-bit integer, pressure in Pas- } \\
\text { cals, scale factor } 1.0 \text {, water vapor in } \\
\mathrm{kg} / \mathrm{m} 2 \text {, scale factor } 0.01 \text {, air tempera- } \\
\text { ture in Kelvin, scale factor } 0.01\end{array}$ & $\begin{array}{l}\text { NCEP REANALY- } \\
\text { SIS }\end{array}$ & HDF4 file. \\
\hline & Global GCMDEM & Meters & & HDF4 file. \\
\hline \multirow[t]{4}{*}{ Indsrbm } & $\begin{array}{l}\text { Surface reflectance input parameter file } \\
\text { (lndsr.txt) }\end{array}$ & & lndpm & Text file. \\
\hline & Landsat surface reflectance product & Reflectance & lndsr & HDF4 file. \\
\hline & Landsat thermal band brightness temperature & ${ }^{\circ}$ Celsius & lndcal & HDF4 file. \\
\hline & $\begin{array}{l}\text { NCEP REANALYSIS data (pressure, water } \\
\text { vapor, air temperature) }\end{array}$ & $\begin{array}{l}\text { Signed } 16 \text {-bit integer, pressure in Pas- } \\
\text { cals, scale factor } 1.0 \text {, water vapor in } \\
\mathrm{kg} / \mathrm{m} 2 \text {, scale factor } 0.01 \text {, air tempera- } \\
\text { ture in Kelvin, scale factor } 0.01\end{array}$ & $\begin{array}{l}\text { NCEP REANALY- } \\
\text { SIS }\end{array}$ & HDF4 file. \\
\hline \multirow[t]{2}{*}{ Indapp } & Landsat surface reflectance product & Reflectance & $\operatorname{lndsr}$ & HDF4 file \\
\hline & Landsat thermal band brightness temperature & ${ }^{\circ}$ Celsius & lndcal & HDF4 file \\
\hline
\end{tabular}

"DEM digital elevation model, DN digital number, ETM+ Enhanced Thematic Mapper Plus, GCM Global Climate Model, GeoTIFF Georeferenced Tagged Image File Format, GNEW new revised gain variable for Landsat 5 TM, GOLD old gain variable for Landsat 5 TM, HDF Hierarchical Data Format, HDF4 HDF version 4, L1 level 1, LPGS Level 1 Product Generation System, NCEP National Centers for Environmental Prediction, NLAPS National Landsat Archive Processing System, OMS Total Ozone Mapping Spectrometer, QA quality assurance, TM Thematic Mapper, TOA top of atmosphere, UL upper left, UMD University of Maryland, WO work order. 
Table 2. Algorithm outputs.

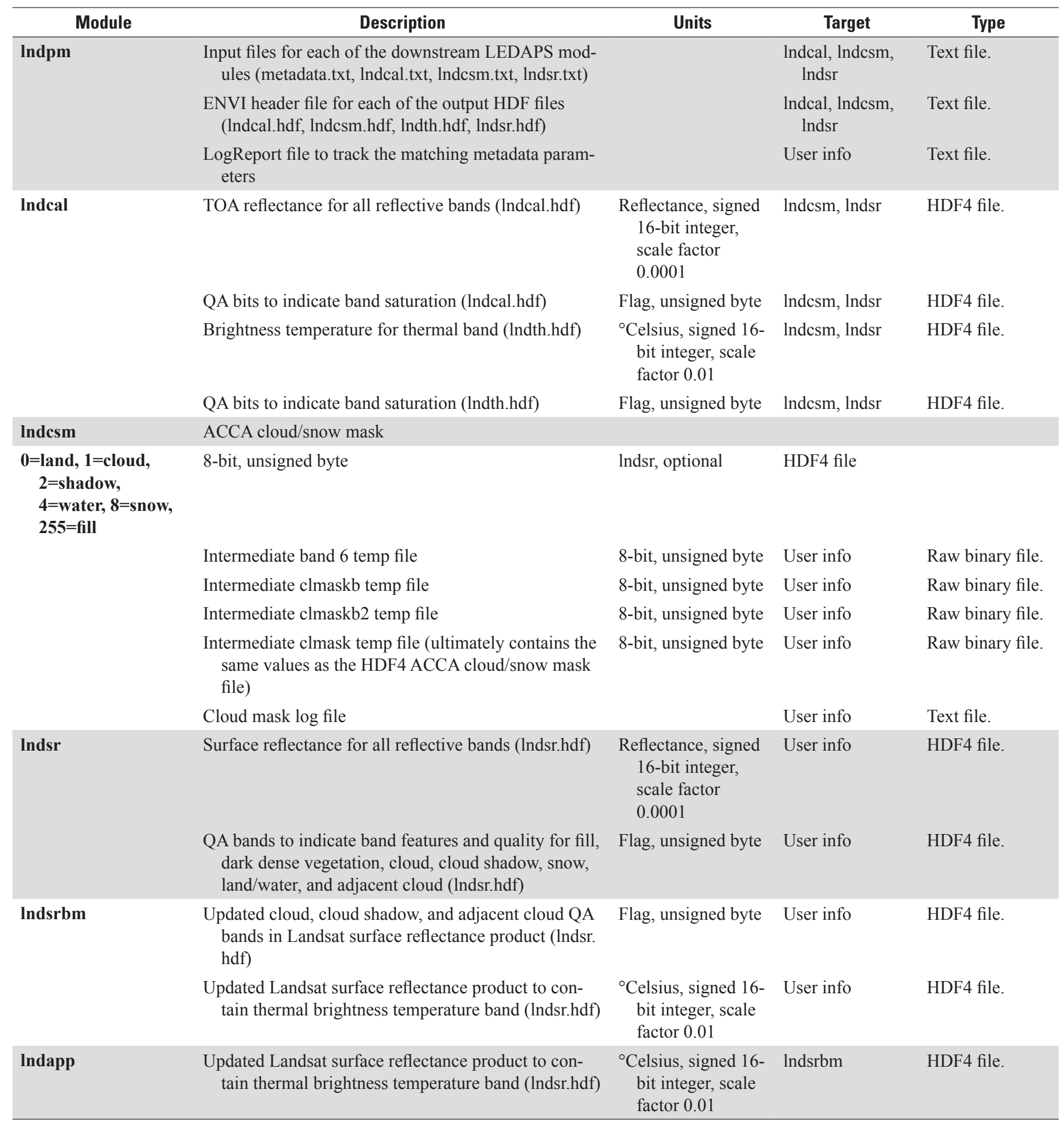

"ACCA Automated Cloud Cover Assessment, ENVI Exelis Visualization Solutions, HDF Hierarchical Data Format, HDF4 HDF version 4, LEDAPS Landsat Ecosystem Disturbance Adaptive Processing System, QA quality assurance, TOA top of atmosphere. 


\section{Inputs}

The inputs required for each of the LEDAPS software modules are listed in table 1. The modules build upon each other, using output from one as input to another, as well as incorporating auxiliary datasets, as needed.

LEDAPS atmospheric correction utilizes external inputs from

- $\quad$ National Centers for Environmental Prediction (NCEP) meteorological reanalysis data,

- $\quad$ NASA GSFC Ozone Monitoring Instrument (OMI),

- $\quad$ NASA GSFC Meteor-3 and Nimbus-7 Total Ozone Mapping Spectrometer (TOMS),

- $\quad$ National Oceanic and Atmospheric Administration (NOAA) Television and Infrared Observation Satellite (TIROS) Operational Vertical Sounder (TOVS), and

- $\quad$ Global Climate Model (GCM) DEM.

The daily atmospheric inputs to LEDAPS 1.0.0 are needed for the acquisition date of the desired Landsat scene. OMI, TOMS, and NCEP REANALYSIS from 1980 to 2013 are available for download from their respective data centers. In cases where TOMS data are not available (for example, 1994-96), TOVS data are used. Scripts developed at USGS EROS are used to download the inputs, sort the files by years, save them to subdirectories, and reformat them into Hierarchical Data Format (HDF). USGS EROS also holds the GCMDEM HDF file delivered with the LEDAPS source code.

Table 1 includes listings for "GOLD" and "GNEW" auxiliary files. These are gain variables for each spectral band utilized to recalibrate the Landsat 5 TM products, but because LEDAPS pulls gain and bias values from the input-product metadata, the default is to skip this recalibration function. The "old" versus "new" is used to distinguish between the file applied to remove the original calibration values and the one that correctly recalculates them. The GOLD_2003 file is applied to products acquired after 2003. These files are delivered with the LEDAPS source code and can be obtained from USGS EROS, if needed.

LEDAPS is configured to read all standard Landsat metadata, as generated by Level 1 Product Generation System (LPGS), National Landsat Archive Production System (NLAPS), or the University of Maryland (UMD). Files with extensions "*MTL.txt" or "*.met” are treated as ETM+ metadata from LPGS. Extensions “*H1," “*.hdr," "*_WO," and "*.prodreport" are treated as TM metadata from NLAPS. UMD metadata file extensions are simply "*.umd" or "*.UMD," but the USGS implementation of LEDAPS 1.0.0 phased out handling UMD input files.

\section{Outputs}

As mentioned previously, the LEDAPS modules build upon each other by producing files or information that are used as input in the subsequent steps. The outputs are listed in table 2 .

\section{Prototype Code}

LEDAPS 1.0.0, as implemented by the USGS, was derived from a February 2011 prototype version of LEDAPS, which was adapted by Feng Gao and available at ftp://hydrolab.arsusda.gov/pub/fgao/Ledaps/(accessed November 9, 2012).

\section{Verification Methods}

Given that the LEDAPS software is already in place and validated (Masek et al., 2006), the production version of LEDAPS, which is used for Landsat Surface-Reflectance generation, can be validated against the existing software. Any changes made to the baseline LEDAPS 1.0.0 code will need to be independently validated, based on the type of change that is made.

\section{Maturity}

The LEDAPS software is stable, and the USGS expects only limited and (or) minor modifications from the original developers of the code. Future enhancements are planned to support additional Landsat satellites (such as Landsat 8, 2013). 


\section{Procedure}

LEDAPS 1.0.0 strings six software modules together to step through the processes of creating TOA and surface-reflectance with quality information. A general description of each module is provided below, followed by programming details, as necessary. "Module 3 Cloud Shadow Mask (lndcsm)" is included for posterity though that software is not used in LEDAPS 1.0.0 (owing to its outdated and inaccurate calculations).

\section{Module 1 Parameter}

The lndpm application reads the input Landsat TM or ETM+ metadata and LEDAPS-related environment variables, calculates the gain and bias (for LPGS products), and generates the parameter files needed for each of the downstream-processing applications. The algorithm processes through these steps:

- Determine the location of the auxiliary files (DEM, OMI/TOMS, REANALYSIS, etc.)

- Read desired fields from the input Landsat metadata or work-order file

- Calculate the band gain and bias, if processing the LPGS products; otherwise use the gain and bias settings in the metadata file

- $\quad$ Read the upper left (UL) corner coordinates, number of lines/samples, and resolution from band 1

- Always convert/use the UL corner of the UL pixel in LEDAPS

- Write the metadata to the meatadata.txt file

- Write the ENVI header files for each of lndcal.hdf, lndth.hdf, and lndsr.hdf

- Create the lndcal.txt metadata file

- Create the lndth.txt metadata file

- Create the Indsr.txt metadata file

\section{Module 2 Calibrate}

The Indcal application reads the sensor and scene information from the input parameter and metadata files. Gains, biases, and other reflectance parameters are read from the input parameter and metadata files. In the unlikely event these parameters are not available in the metadata, LEDAPS has functionality to perform recalibration based on the band and sensor using the "GOLD" and "GNEW" files. The brightness temperature is computed and written to lndth.hdf, with saturated and fill values being modified in the output and flagged in the quality-assurance (QA) band. The TOA reflectance values are calculated for each band and written to lndcal.hdf, with saturated and fill values being modified in the output and flagged in the QA band. Associated metadata is written to both files. The application also outputs statistics - such as the minimum and maximum reflectance per band - to the user. There are three steps to complete processing in this module: calibration, computation of brightness temperature, and TOA reflectance.

\section{Calibration}

- Read the input header file (metadata.txt), which contains sensor, acquisition date, solar angles, path/row, scene information, projection information, and gain/bias information

- Set the thermal gain to 0.0551583 and bias to 1.2377996

- Set the line minimum and maximum (LMIN/LMAX) values for each band and sensor (this includes different LMIN/ LMAX values for ETM+ before/after July 1, 2000)

- Set the relative sun-earth distance values for each band and sensor

- Verify the acquisition date based on the sensor type

- Set the qcalmin $=1$ (assume LPGS) and qcalmax $=255$

- Compute the gain/bias for each band, based on the band and sensor-specific variables

$\circ \quad$ Set gain $=(\operatorname{lmax}-\operatorname{lmin}) /($ qcalmax - qcalmin $)$

- Set bias $=\operatorname{lmin}-($ gain $*$ qcalmax $)$

- If the satellite is Landsat 1-3 and the gain/bias for a particular band is less than delta (0.00001), then recompute the gain/bias based on band and sensor-specific variables

○ Set gain $=10.0 *(\operatorname{lmax}-\operatorname{lmin}) / 254.0$

○ $\quad$ Set bias $=10.0 * \operatorname{lmin}$

$\circ$ If processing Landsat 1 and band 4

- $\quad$ Set gain $=0.6024$

- Set bias $=10.0 *(\operatorname{lmax}-\operatorname{lmin}) / 254.0$

- If the satellite is Landsat 4 or 5 and the gain/bias for a particular band is less than delta (0.00001), then recompute the 
gain/bias based on band and sensor-specific variables

$\circ \quad$ If this is band 1

○ Else

- Set the $\mathrm{K} 1$ and $\mathrm{K} 2$ constants to sensor-specific values

- $\quad$ Set gain $=10.0 *(\operatorname{lmax}-\operatorname{lmin}) / 254.0$

- $\quad$ Set bias $=10.0 * \operatorname{lmin}$

- If processing Landsat $5 \mathrm{TM}$ and the recalibrate flag was set, read the old and new calibration coefficients from GOLD/ GOLD_2003 and GNEW

- Create and open the output files (lndcal.hdf and lndth.hdf)

Computation of Brightness Temperature

- Compute the brightness temperature for band 6; keep track of $\min / \max$ band statistics

$\circ$ If dnout is set

- $\quad$ Set scale $=\left(d n \_m a p[3]-d n \_m a p[2]+1\right) /\left(d n \_m a p[1]-d n \_m a p[0]+1\right)$

- Set rad $=$ gain $*$ current thermal pixel value

- Set temp $=\mathrm{K} 2 /(\log (1.0+\mathrm{K} 1 / \mathrm{rad}))$

$\circ \quad$ Set temp $=273.15$

- If dnout is set $\circ$ Else

- Set brightness temp $=$ dn_map[2] $+($ current thermal pixel value - dn_map[0] $) *$ scale $)+0.5$

- $\quad$ Set brightness temp $=$ temp $* 100.0+0.5$

- If the input thermal value is $\geq 254$, then set the QA saturated band flag for band 6 and mark the output pixel value as "saturated" (i.e., 20,000)

- If the input thermal value is fill, then set the QA fill flag for band 6 and mark the output pixel value as "fill" (i.e., -9999)

- Write the temp to the HDF file

- Write the stats to the screen

- Write the QA band to the HDF file

- Write the band 6 metadata

\section{Computation of TOA Reflectance}

- Compute the TOA reflectance for each of the reflective bands; keep track of min/max band statistics

$\circ$ If dnout is set

- Set scale $=\left(d n \_m a p[3]-d n \_m a p[2]+1\right) /\left(d n \_m a p[1]-d n \_m a p[0]+1\right)$

$\circ$ If the GOLD and GNEW files are available, and the recal flag is set

- If the work order flag is set

- Set alpha = final_gain for this band

- $\quad$ Set grescale = DN_to_Radiance_gain for this band

- $\quad$ Set gold $=$ alpha/grescale

- Else

- Set gold $=$ GOLD gain for this band

- $\quad$ Set gnew $=$ GNEW gain for this band

$\circ$ Else

- End if

$\circ$ End if

- $\quad$ Set gold $=1.0$

- Set gnew $=1.0$

- $\quad$ Set gain = gain

- $\quad$ Set bias $=$ bias * gold $/$ gnew

- $\quad$ Set ref_conv $=(\mathrm{PI} *$ dsun 2$) /($ esun * cos_sun_zenith $)$

- If the input reflective value is 255 , then set the QA saturated band flag for this band, and mark the output pixel value as "saturated" (i.e., 20,000)

- Else If the input reflective value is fill, then set the QA fill flag for this band and mark the output pixel value as "fill" (i.e., -9999)

- Else

$\circ \quad$ Set rad $=($ gain $*$ current pixel value $)+$ bias 
- If the dnout is set

- Set ref $=$ rad $*$ ref_conv

- Else

- Set the output for the current pixel and band $=\left(\mathrm{dn}_{-} \operatorname{map}[2]+\left(\right.\right.$ current pixel value $-\mathrm{dn} \_$map $\left.[0]\right) *$ scale $)+0.5$

○ Set the output for the current pixel and band $=(\operatorname{ref} * 10,000.0)+0.5$

- Write the TOA reflectance to the HDF file

- Write the stats for each band to the screen

- Write the QA band to the HDF file

- Write the reflective band metadata

\section{Module 3 Cloud Shadow Mask}

A description of this module is included herein for posterity. It was formerly used as a preliminary cloud filter in production, but was deactivated in LEDAPS 1.0 .0 because it uses a $C$ translation of pre-2004 heritage ACCA code and was not particularly successful in its calculations. The lndcsm application opens, reads, and applies a scale factor to the lndcal and lndth values. The brightness temperature values are converted from degrees Celsius $\left({ }^{\circ} \mathrm{C}\right)$ to Kelvin. All fill pixels are marked as such, otherwise the pixels are initialized as land pixels. Various band ratios are then computed for each pixel (such as the normalized difference snow index (NDSI)) and compared to known threshold values for cloud-, snow-, and water-related pixels. The respective QA mask is then written to the lndcal.hdf file, along with associated metadata.

\section{Module 4 Surface Reflectance}

The lndsr algorithm performs the atmospheric correction needed to calculate surface-reflectance for Landsat TM and ETM+ data. $6 \mathrm{~S}$ is run to generate a look up table (LUT) accounting for pressure, water vapor, ozone, and geometrical conditions over the whole scene for a range of aerosol optical thicknesses (AOT). A LUT is created for every band and is used both in the aerosol retrieval process as well as in the correction step. Incorporating the DDV method developed by Kaufman and others (1997), AOT is extracted directly from the imagery based on the physical correlation between chlorophyll absorption and bound water absorption. A linear relation is created between shortwave infrared (SWIR) and surface-reflectance in visible bands so that AOT can be estimated by comparing visible band surface-reflectance with TOA reflectance.

AOT is averaged to 1-kilometer $(\mathrm{km})$ resolution, and candidate dark targets are selected in the image. The relation between blue and SWIR reflectance is derived over the dark targets and propagated across the spectrum using a continental aerosol model. 6S is summarized in figure 3, excerpted from Vermote and Saleous (2007).

- Open and read the input parameter file

- Open the input thermal band

- Open and read the REANALYSIS "PRWV" file

- Open and read the ozone file

- Create the look up table for parameters required as part of the surface-reflectance calculations

- Create and open the output file (lndsr.hdf)

- Determine the scene center latitude/longitude (lat/long) in degrees

- If the acquisition date are known

- Compute the scene Greenwich Mean Time (GMT) based on the acquisition time

- Else

○ Compute the scene GMT $=10.5-$ center_long/15

- If scene GMT is $<0$, then adjust scene GMT by 24 hours

- Read the surface pressure, water vapor, and air temperature data and auxiliary metadata from the PRWV file

- Read the auxiliary data and associated metadata from the ozone file

- Convert the surface-pressure values from Pascals to millibars

- Convert the water vapor from kilograms per square meter $\left(\mathrm{kg} / \mathrm{m}^{2}\right)$ to grams per square centimeter $\left(\mathrm{g} / \mathrm{cm}^{2}\right)$ 


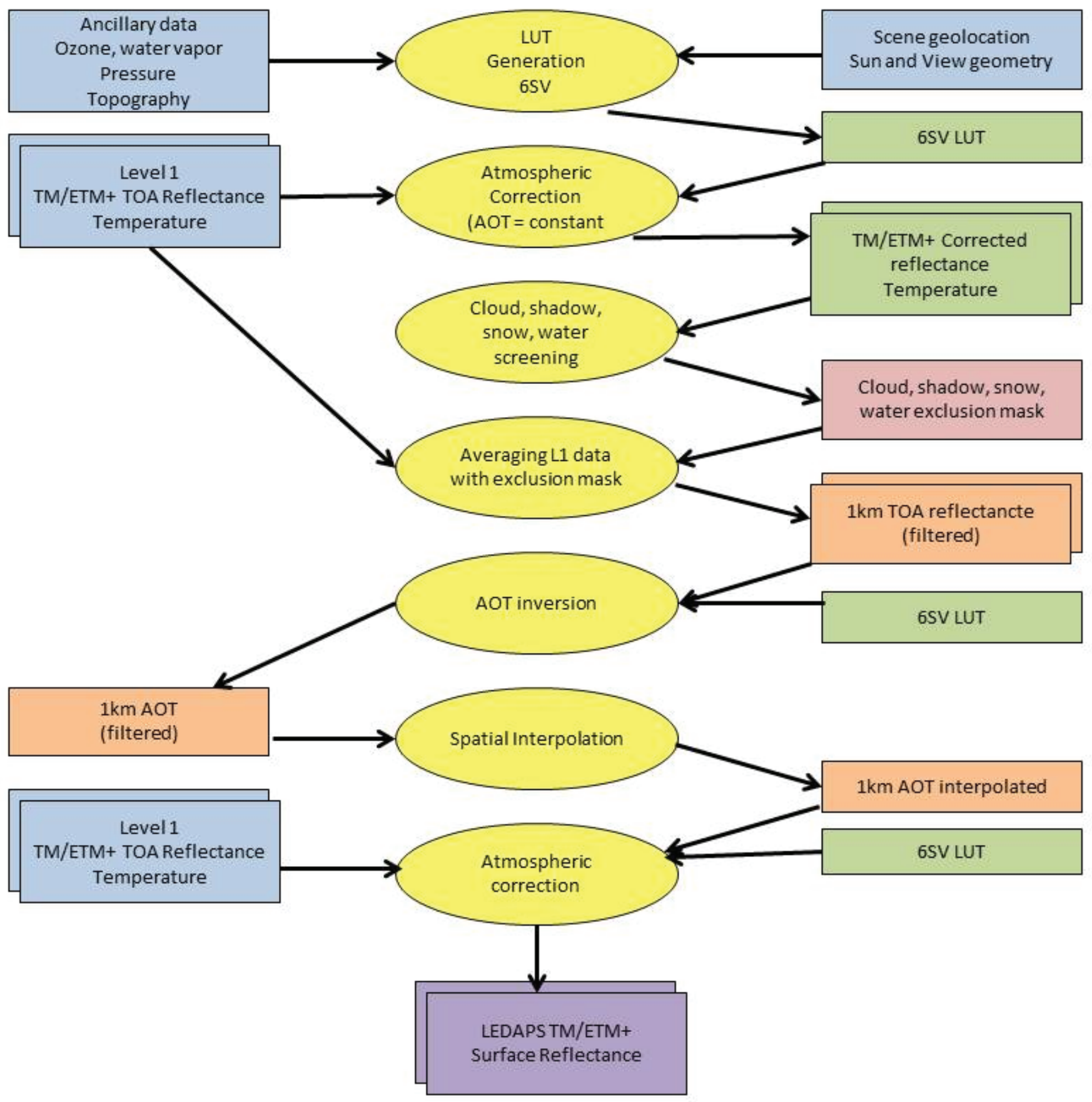

Figure 3. Atmospheric correction flow. 
- Convert the ozone data to centimeters-atm

- $\quad$ Read the DEM file

- Determine the scene center lat/long, in degrees (duplicate code)

- Compute the true north adjustment

- Interpolate the water vapor auxiliary data to obtain values for the scene center

- Interpolate the ozone auxiliary data to obtain values for the scene center

- Run the $6 \mathrm{~S}$ code and compute the atmospheric-correction parameters using the following

- Set target altitude to $0 \mathrm{~km}$ (sea level)

- Set sza to solar zenith, in degrees

- Set phi to solar azimuth, in degrees

- Set vza $=0$

- Set month $=9$

$\circ \quad$ Set day $=15$

- Set srefl $=0.14$

- Interpolate the water vapor, ozone, and surface pressure auxiliary data to obtain values for each of the aerosol grid cells (40x40 window)

- Get the surface pressure DEM data values for each of the aerosol grid cells (40x40 window)

- Update the auxiliary surface-pressure values in the aerosol grid = surface pressure DEM * surface pressure auxiliary / $1,013.0$

- Compute the atmospheric parameters with aot550 $=0.01$ for each point in the aerosol grid cell, using the parameters in the $6 \mathrm{~S}$ tables

- For each image line

- Read the reflectance band data for the current line

- Read the QA data for the current line

- Read the thermal band for the current line

- Interpolate the air temperature for every point in the aerosol grid

- Run the first pass cloud screening and compute the statistics/diagnostics for the CELLHEIGHT_5KM x CELLWIDTH_5KM (160x160) grid

- For each line in the cloud diagnostics grid

$\circ \quad$ For each sample in the cloud diagnostics grid

- If (nb_tb_clear $\leq 0)$

- $\quad$ Set avg_t6_clear $=-9999$

- $\quad$ Set avg_b7_clear $=-9999$

- $\quad$ Set std_t6_clear $=-9999$

- $\quad$ Set std_b7_clear $=-9999$

- Continue

- Set coef $=($ scene_gmt - air_temp_time[current_layer] $) /$ air_temp_time_resolution

- Interpolate the air temperature for the current pixel

- Set the airtemp_2m $=(1$-coef $) *$ air_temp[current_layer] + coef*air_temp[current_layer+1]

- Set sum_value = average of the clear temperature (b6) values for the current pixel in the grid

- Set sumsq_value $=$ stddev clear temperature (b6) value for the current pixel in the grid 
- Compute the avg_t6_clear value = sum_value / number of clear temp (b6) values for the current pixel in the grid

- If the number of clear temp (b6) values for this pixel is greater than 1

- Set std_t6_clear $=($ sumsq_value - sum_value**2 / number of clear temp (b6) values) $/$ (number of clear temp (b6) values - 1)

- Set std_t6_clear $=\operatorname{sqrt}($ fabs(std_t6_clear) $)$

- Else

- $\quad$ Set std_t6_clear $=0$

- Set sum_value $=$ average of clear b7 values for the current pixel in the grid

- Set sumsq_value = stddev of clear b7 values for the current pixel in the grid

- Set avg_b7_clear = sum_value / nb_t6_clear

- If the number of clear temp (b6) values for this pixel is greater than 1

- Set std_b7_clear $=\left(\right.$ sumsq_value - sum_value ${ }^{* * 2} /$ number of clear temp (b6) values $) /$ (number of clear temp (b6) values - 1)

- Set std_b7_clear=sqrt (fabs(std_b7_clear)

- Else

- $\quad$ Set std_b7_clear $=0$

- Fill in (interpolate) the missing value in the t6_clear grid based on existing values

- Create the dark target temporary file

- For each image line in the aerosol region

- Read the reflectance band data for the current line

- Read the QA data for the current line

- Read the thermal band for the current line

- Run the second pass cloud screening

- Dilate the cloud shadow mask for the adjacent $5 \times 5$ window

- Write the dark target information to the temporary file

- Close the temporary file

- Reopen the dark target temporary file

- For each line

- Read the DDV from the temporary file for the current aerosol region

- Read each band for the current aerosol region

- Compute the aerosol for the region (function call)

- Write the dark target map to the temporary file

- Close the dark target temporary file

- Fill the gaps in the coarse resolution aerosol product for bands 1, 2, and 3

- Compute the atmospheric coefficients for the whole scene using the retrieved AOT

- Reopen the dark target temporary file

- For each line

- Read the current line for each reflective band

- Read the current line for the thermal band

- Compute the surface-reflectance for the current line and stats (function call) 
- For each line

- For each sample

- For each band

- If the current pixel in the current band is not the max SR value

- $\quad$ Set rho $=$ current pixel / 10,000.0

- Set rho $=$ rho / atmos_coef_tg0G - atmos_coef_rho_ra

- Set tmpflt $=$ atmos_coef_tgH20*atmos_coef_td_ra $*$ atmos coef_tu_ra

- $\quad$ Set rho $=$ rho $/$ tmpflt

- $\quad$ Set rho $=$ rho / $(1+$ atmos_coef_S_ra $*$ rho $)$

- $\quad$ Set line_out for the current pixel and band to rho * 10,000.0

- Else

- Set line_out for the current pixel and band to max SR value

- Compute the $\min / \max$ statistics

○ Read the dark target information for the current line from the temporary file

○ For each sample

- Initialize the QA data (fill, DDV, cloud, shadow, snow, water, adjacent cloud) for the current pixel to OFF

- If the current pixel is not fill

- Interpolate the AOT for the current pixel from the aerosol grid

- If the DDV value AND 0x01 then turn on the dark target flag

- If the DDV value AND 0x10 then

○ Turn off the land flag

- Else

○ Turn on the water flag

- If the DDV value AND 0x20 then turn on the internal cloud mask flag

- Copy the aerosol stats band 1 to the output DARK band

- Copy the aerosol stats band 2 to the output AVG_DARK band

- Copy the aerosol stats band 3 to the output STDDEV_DARK band

- Else

- Set the output values for this pixel to fill

- Reset the cloud shadow and adjacent cloud values to OFF

- $\quad$ Set anom = band 1 current pixel - band 3 current pixel / 2.0

- $\quad$ Set t6 $=$ thermal current pixel / $100.0+273.0$

- Set t6s_seuil $=280.0+(1,000.0 * 0.01)$

- If (((anom > 300) AND (band5 current pixel > 300) AND (t6 < t6s_seuil)) OR ((band 3 current pixel $>5,000)$ AND $($ t6 < t6s_seuil) $))$

- $\quad$ Turn cloud flag to $\mathrm{ON}$

- Else

- $\quad$ Turn cloud flag to OFF

- Write each of the output reflective bands as 16-bit products 
- Write each of the output QA bands as unsigned 8-bit products

- Print the statistics for each band

- Write the output metadata for each band

- $\quad$ Close all the files

- Write the spatial metadata to the HDF file

\section{Module 5 Surface-Reflectance Based Mask}

The lndsrbm application includes the process that appends the brightness temperature band to the surface-reflectance product. The surface-reflectance product is read, along with the metadata, and the scene center is computed. The auxiliary data are read for the scene center and acquisition date. The air temperature, solar zenith, solar azimuth, northern adjustment, and pixel size are all used to determine cloud-related properties. The cloud-related QA band values are reset/cleared, ignoring what was previously set in the lndsr application. Bands 1,3,5, and 6 are used to determine cloudy pixels, and the average clear temperature is computed for the non-cloudy pixels. For every cloudy pixel, the $5 \times 5$ surrounding window is marked as adjacent cloud, unless the pixel is already marked as a cloud. For every cloudy pixel, the cloud shadows are determined. For every cloud shadow, the $3 \times 3$ surrounding window is marked as cloud shadow if it is not already cloud or adjacent cloud. The updated cloudrelated QA information and associated metadata are written to the surface-reflectance product, overwriting the previous cloudrelated QA bands.

- Get name of SR_FILE, TEMP_FILE, and PRWV_FILE from the input parameter file and make sure they exist

- Append the thermal band to the surface-reflectance product (using lndapp)

- Get the bounding coordinates from the surface-reflectance file

- Compute the scene center lat/long

- $\quad$ Read the REANALYSIS data from the PRWV_FILE for the scene center and acquisition date

- Get the air temp for the scene center and acquisition date

- Compute the scene orientation

- Compute the deviation between the center and a point 100 pixels north from center (adjnorth)

- Read the solar azimuth and solar zenith from the input metadata

- Read the pixel size from the input metadata

- Write the air temp (tclear) in Kelvin, solar zenith (ts), 0.0 (tv), solar azimuth (fs), adjnorth, and pixel size to a temporary text file

- $\quad$ Set $\mathrm{cfac}=6.0$

- $\quad$ Set dtr $=\operatorname{atan}(1.0) / 45.0$

- $\quad$ Set default pixsize $=28.5$

- Read tclear, ts, tv, fs, tna, and pixsize from the temporary input file

- Subtract 273.0 from tclear to convert Kelvin to ${ }^{\circ}$ Celsius

- Open the input surface-reflectance product

- Get the number of lines and samples from the cloud QA

- Allocate memory for the various surface-reflectance, temperature, QA bands, and a temporary bit used for the cloud detection

- Read the cloud QA, cloud shadow QA, adjacent cloud QA, snow QA, temperature band, band 1, band 2, band 3, and band 5 .

- Reset/clear the cloud, cloud shadow, and adjacent cloud bits (ignoring what was set in the lndsr application)

- \# Update the cloud QA bit

- For each line

- For each sample

- If band1 pixel is not fill

$\circ \quad$ Increment the number of values count by 1

- Set anom $=$ band 1 pixel - band 3 pixel $/ 2.0$

- Set $\mathrm{t} 6=$ temperature pixel $/ 100.0$

$\circ$ If this is a snow pixel then

- Continue

- Else

- If (anom > 300) and (band5 pixel $>300)$ and (t6 < tclear) then

- Set the cloud QA for this pixel to cloudy 
- Increment the number of cloudy pixels count by 1

- Else

- If (band $1>3,000$ ) and ( $\mathrm{t} 6<$ tclear) then

- Set the cloud QA for this pixel to cloudy

- Increment the number of cloudy pixels count by 1

- Else

- Increment mclear by t6/10,000.0

- Increment number of clear pixels count by 1

- $\quad$ End if

- End if

$\circ$ End if

- $\quad$ End if

- End for samples

- $\quad$ End for line

- If the number of clear pixels $>0$

$\circ$ Set mclear $=$ mclear $* 10,000 /$ number of clear pixels to produce the average clear temp

- $\quad$ End if

- Set pclear $=$ number of clear pixels $* 100 /$ number of values count to produce the percentage of clear pixels

- If pclear $>5$ then

- Set tclear $=$ mclear

- $\quad$ End if

- \# Update the adjacent cloud QA bit

- For each line

- For each sample

- If this pixel is a cloud

- For $\mathrm{k}=$ line -5 to line +5

- $\quad$ For $1=$ sample -5 to sample +5

- If this window pixel $(\mathrm{k}, \mathrm{l})$ is an adjacent cloud or a cloud

- Continue

- Else

○ Set this pixel $(\mathrm{k}, \mathrm{l})$ as an adjacent cloud pixel

- $\quad$ End if

- End for 1

○ End for $\mathrm{k}$

- End if cloudy pixel

- $\quad$ End for line

- End for sample

- \# Compute the cloud shadow

- $\quad$ fack $=$ cosine $(\mathrm{fs} * \mathrm{dtr}) *$ tangent $(\mathrm{ts} * \mathrm{dtr}) /$ pixsize

- $\quad$ facl $=$ sine $(\mathrm{fs} * \mathrm{dtr}) *$ tangent $(\mathrm{ts} * \mathrm{dtr}) /$ pixsize

- For each line

- For each sample

- If the pixel is a cloud

- Set tcloud $=$ pixel temperature

- Set cldh $=($ tclear - tcloud $) * 1,000.0 /$ cfac

$\circ$ If cldh $<0$ then set cldh $=0$

- Set cldhmin $=$ cldh $-1,000$

- Set cldhmax $=$ cldh $+1,000$

- Initialize minimum band5 value $=9,999$

- For icldh $=$ cldhmin $/ 10$, cldhmax $/ 10$

- $\quad$ Set cldh $=$ icldh $* 10$

- Set $\mathrm{k}=$ line + fack $*$ cldh

- Set $1=$ sample - facl $*$ cldh

- If (band5 pixel $(\mathrm{k}, \mathrm{l})<800)$ and (band2 pixel $(\mathrm{k}, 1)$ - band3 pixel $(\mathrm{k}, \mathrm{l})<100)$

- If this is an adjacent cloud or a cloud or a cloud shadow pixel $(\mathrm{k}, \mathrm{l})$ then - Continue

- Else 
- If band5 pixel $(\mathrm{k}, 1)<$ minimum band5 pixel then

- Set minimum band5 pixel = band5 pixel $(\mathrm{k}, 1)$

- Store line and sample location of the minimum band5 pixel $(\mathrm{k}, \mathrm{l})$ $\circ$ End if

- $\quad$ End if

- End if

$\circ \quad$ End for icldh

- If the minimum band5 pixel value was set

- Set the pixel with the minimum band5 pixel line, sample as a cloud shadow

$\circ$ End if

- End if cloudy pixel

- End for line

- End for sample

- \# Dilate the cloud shadow

- For each line

- For each sample

- If this pixel is a cloud shadow

- For $\mathrm{k}=$ line -3 to line +3

- For $1=$ sample-3 to sample +3

- If this is an adjacent cloud or a cloud or a cloud shadow pixel $(k, 1)$ then

- Continue

- Else

- If tmpbit is set to on for this pixel $(\mathrm{k}, \mathrm{l})$ then

- Continue

- Else

- Set tmpbit to on for this pixel $(\mathrm{k}, \mathrm{l})$

$\circ$ End if

- $\quad$ End if

- End for 1

- End for $\mathrm{k}$

- End if

- End for line

- End for sample

- \# Update the cloud shadow

- For each line

- For each sample

- If tmpbit is set for this pixel then

- Set this pixel as a cloud shadow

- Set tmpbit to off for this pixel

- End if

- End for sample

- $\quad$ End for line

- Write the new cloud, cloud shadow, and adjacent cloud bands to the surface-reflectance product

\section{Module 6 Append}

The lndapp application reads the thermal band from the thermal brightness temperature file (band 6) and appends that band to the surface-reflectance file. Associated metadata for this band also are written. This module is a sub-process within "Module 6 Surface-Reflectance Based Mask."

- Open the input surface-reflectance file and read metadata from "band1"

- Open the input thermal-brightness file and read metadata from "band6"

- If number of rows and columns from band 1 and band6 don't match, then exit with an error

- Read the image data from band6 in the thermal-brightness file and append to the surface-reflectance product as band6

- Write metadata for band6

- Close surface-reflectance file

- Close thermal-brightness file. 


\section{References Cited}

Kaufman, Y.J., Wald, A.E., Remer, L.A., Gao, B.-C., Li, R.-R., and Flynn, L., 1997, The MODIS 2.1- $\mu$ m channel-correlation with visible reflectance for use in remote sensing of aerosol: IEEE Transactions on Geoscience and Remote Sensing, v. 35, no. 5 , p. $1286-1298$.

Kotchenova, S.Y., Vermote, E.F., Matarrese, Raffaella, and Klemm, F.J., Jr., 2006, Validation of a vector version of the 6S radiative transfer code for atmospheric correction of satellite data-Part I-Path radiance: Applied Optics, v. 45, no. 26, p. 6762-6774.

Masek, J.G., Vermote, E.F., Saleous, N.E., Wolfe, R., Hall, F.G., Huemmrich, K.F., Gao, Feng, Kutler, J., and Lim, T.K., 2006, A Landsat surface-reflectance dataset for North America, 1990-2000: IEEE Geoscience and Remote Sensing Letters, v. 3, no. 1 , p. 68-72.

National Aeronautics and Space Administration, 2007, User guides for L7ESR, accessed October 9, 2012, at http://ledaps. nascom.nasa.gov/docs/docs.html.

Vermote, E.F., Tanre, D., Deuze, J.L., Herman, M., and Morcrette, J.-J., 1997, Second simulation of the satellite signal in the solar spectrum, 6S-An overview: IEEE Transactions on Geoscience and Remote Sensing, v. 35, no. 3, p. 675-686.

Vermote, Eric, and Saleous, Nazmi, 2007, LEDAPS surface-reflectance product description (ver. 2.0), 21 p., accessed October 9, 2012, at http://ledaps.nascom.nasa.gov/docs/pdf/SR_productdescript_dec06.pdf.

Wolfe, R., Masek, J., Saleous, N., and Hall, F., 2004, LEDAPS—Mapping North American disturbance from the Landsat record, in Proceedings of the IEEE International Geoscience and Remote Sensing Symposium, September 19-26, 2004, Anchorage, Alaska.

Publishing support provided by:

Rolla Publishing Service Center

For more information concerning this publication, contact:

U.S. Geological Survey Earth Resources Observation and Science (EROS) Center

47914 252nd Street, Sioux Falls, South Dakota 57198

(605) 594-6151

Or visit the EROS Center Web site at:

http://eros.usgs.gov/ 



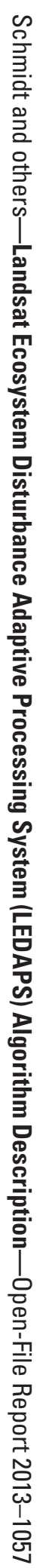

